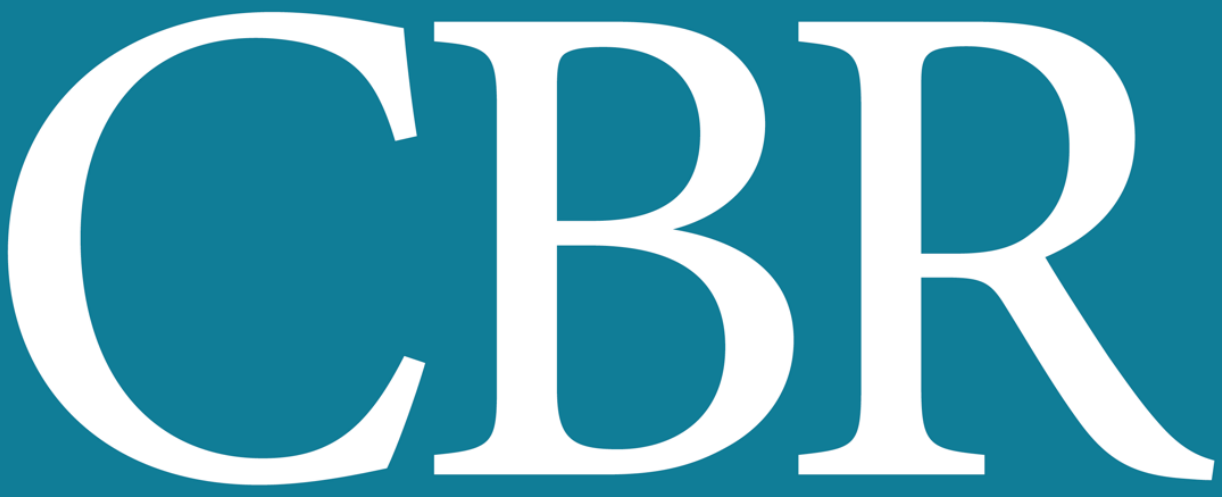

INTERNATIONAL JOURNAL OF CANCER AND BIOMEDICAL RESEARCH

https://jcbr.journals.ekb.eg

Editor-in-chief

Prof. Mohamed Labib Salem, PhD

Assessment of the clinical value of red cell distribution width in patients with de novo hepatocellular carcinoma following HCV clearance with the direct-acting antiviral agents

Haidi K. Ramadan, Eman M. Nagiub, Hanan A. Eltyb and Mahmoud M Mohammed 


\section{Welcome letter from Editor-in-Chief}

Welcome to the Int J Cancer and Biomedical Research (IJCBR)!

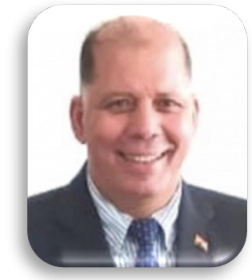

It is with great pleasure that I write this editorial to welcome you to the IJCBR. This journal provides a platform for publication of original and reviews research articles, short communications, letter to editor, thesis abstract, conference report, and case studies. These types of publication are directed at the interface of the fields of cancer and biomedical research.

The IJCBR relies on a distinguished expert of the Advisory and Editorial Board Members from the top international league covering in depth the related topics. They timely review all manuscripts and maintain highest standards of quality and scientific methodology and ethical concepts. Meanwhile, we take all possible means to keep the time of the publication process as short as possible.

I take this chance to welcome your contributions to the IJCBR and have every expectation that it will soon become one of the most respected journals in both the fields of cancer and biomedical research.

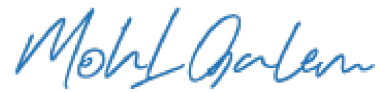

Mohamed L. Salem,

Editor in Chief 


\title{
Assessment of the clinical value of red cell distribution width in patients with de novo hepatocellular carcinoma following HCV clearance with the direct-acting antiviral agents
}

\author{
Haidi K. Ramadan ${ }^{1}$, Eman M. Nagiub², Hanan A. Eltyb ${ }^{3}$ and Mahmoud M Mohammed ${ }^{4}$ \\ ${ }^{1}$ Tropical Medicine and Gastroenterology, Faculty of Medicine, Assiut University, Egypt \\ ${ }^{2}$ Clinical Pathology, Faculty of Medicine, Assiut University, Egypt \\ ${ }^{3}$ Medical Oncology, South Egypt Cancer Institute, Assiut University, Egypt \\ ${ }^{4}$ Surgical Oncology, South Egypt Cancer Institute, Assiut University, Egypt
}

\section{III}

ABSTRACT

Background: The Red cell distribution width (RDW) shows a significant increase both in the hepatitis C virus (HCV) infection and hepatocellular carcinoma (HCC). Treatment of HCV has changed following the introduction of direct-acting antivirals (DAAs) with a higher sustained virological response rate (SVR). However, HCC is still developed after DAAs therapy. Aim: The study aimed to assess the changes of RDW in HCC patients with HCV viremia and after SVR12 to DAAs. Methods: This work is based on a retrospective cohort study including 120 patients allocated into 3 groups, 40 / each. Group 1: patients with HCV-related liver cirrhosis without HCC and not treated with DAAs, group 2: patients with liver cirrhosis and HCC without DAAs and group 3: patients with liver cirrhosis and developed HCC following SVR12 to DAAs. Liver profile, International Normalized Ratio (INR) and creatinine indices were measured with an assessment of Child class CBC for measurement of RDW and RDW/Platelet ratio (RPR) were done. Results: The red distribution width (RDW) was mildly elevated in group 3 compared to group 2 . The ratio of RDW/Platelet was almost similar in group 2 and group 3. RDW increased in group 3 relative to group 2 in all Child classes with a significantly higher level in Child A and B. Conclusion: Clearance of HCV following DAAs did not have a major impact on RDW in HCC patients after DAAs therapy which is not different from viremic patients with HCC.

Keywords: Red cell distribution width; Red cell distribution width/platelet ratio; Direct Acting-Antivirals; Hepatitis C virus

\section{ARTICLE INFO}

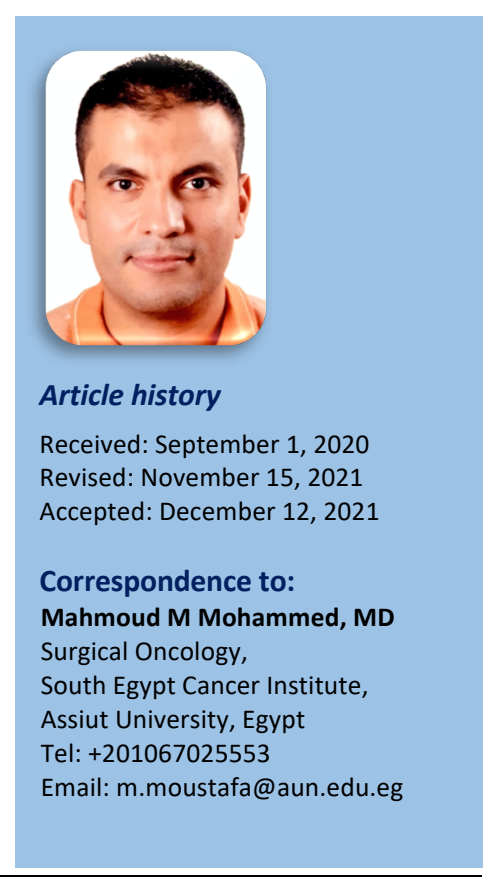

Editor-in-Chief: Prof. M.L. Salem, PhD - Article DOI: 10.21608/jcbr.2021.44109.1072

\section{INTRODUCTION}

Chronic hepatitis $\mathrm{C}$ virus (HCV) is a major cause of liver-related mortality worldwide since it is a key risk factor for the progression of the liver cirrhosis and hepatocellular carcinoma (HCC) (European Association for Study of liver 2014). Hepatocellular carcinoma (HCC) is ranked as the $6^{\text {th }}$ most common cancer disease worldwide and as the second principal cause of cancer-linked deaths approximately $9 \%$ of cancer deaths (Rawla., et al.2018). In HCC patients, prognostic factors are influential in the treatment plan selection of most patients with this type of cancer. Therefore, a multi-marker approach used in combinations represents an effective way for HCC assessment and is of great value for exploring management options (Goyal and $\mathrm{Hu}$ 2017).

Red blood cell distribution width (RDW) is a simple, economical, automatically reported, yet largely overlooked blood test parameter; it reflects the degree of red blood cell size heterogeneity "anisocytosis" in peripheral blood (Salvagno., et al. 2015). Normal reference range of RDW is $11.0 \%$ to $14.0 \%$ (Wang., et al. 2016) It is mainly used to help in identifying the cause of anemia (Lippi and Plebani 2014). Recent studies highlight its importance making RDW assessment crucial far beyond just differentiation of types of anemia (Salvagno., et al. 2015). Accumulating evidence has shown that RDW can be used as an inflammatory 
biomarker in various diseases including cardiovascular diseases (Uyarel., et al. 2012), acute and chronic kidney diseases (Ku., et al. 2012), chronic obstructive pulmonary diseases (Balta., et al. 2014). and critically ill patients (Purtle., et al. 2014). Additionally, RDW has a clinical significance in cancer as assessment disease severity in both liquid and solid malignancies. This relation is based on the fact that disease conditions cause an interacting clinical, biochemical and nutritional imbalance that impact the red cell population dynamics and survival (e.g production, maturation, and turnover). The RDW mirrors this deregulation of erythrocyte homeostasis (Goyal and Hu 2017).

Concerning liver disease association to RDW, it was found to be related to disease severity and level of fibrosis in liver cirrhosis of hepatitis $C$ and in hepatocellular carcinoma (Goyal and $\mathrm{Hu}$ 2017). The ratio of RDW to platelet (RPR) as well can be used as a predictor of fibrosis and cirrhosis in patients with chronic hepatitis (Wang., et al. 2016). Moreover, it has shown a higher accuracy compared to the RDW and MELD score (Taefi., et al. 2015).

The RPR values are considerably elevated in chronic HCV patients and can be utilized to predict advanced damage in liver histology (Karagöz., et al. 2016). However, Thandassery et al. reported that the PRP index showed low predictive accuracy to fibrosis by liver biopsy in chronic HCV (Thandassery., et al. 2016). Inflammation in chronic HCV infection may contribute to increased RDW by inhibiting the response to erythropoietin or the production of erythropoietin and reducing RBC survival. Thus, higher RDW levels are related to increased RBC destruction or ineffective production (Lou., et al. 2012).

Treatment of HCV has been changed following the introduction of direct-acting antivirals (DAAs) with the achievement of high sustained virological response (SVR) reaching 90 - 100\% (Falade-Nwulia., et al. 2017). Thus, the hypothesis is that following DAAs therapy, inflammatory reaction induced by HCV viremia will improve following clearance of the virus and obtaining higher SVR12. This would result in lower RDW in patients with HCC who received DAAs and cleared the viremia in a comparison with HCC who did not receive DAAs with persistent viremia. However, the changes of RDW and RPR values in case of HCC patients in the presence and the absence of HCV following antiviral therapy has not been well-defined i.e whether RDW values changes in association with persistent or absence of viral infection in HCC.

\section{PATIENTS AND METHODS Patients}

In this cross-sectional study, patients were recruited from Tropical Medicine and Gastroenterology Department, at Al-Rajhi Liver University Hospital and Medical Oncology department South Egypt Cancer Institute during the period from January 2019 to January 2020. They were divided into three groups; the first group included patients with HCV-related liver cirrhosis not treated with DAAs and did not have HCC. The second group; patients with HCVrelated liver cirrhosis and $\mathrm{HCC}$ but did not receive DAAs (HCC with viremia). The third group included patients with HCV-related liver cirrhosis and developed de novo HCC following treatment with DAAs with SVR12 (HCC without viremia).

Patient's exclusion criteria included factors that may affect RDW level; autoimmune, renal, hematological disorders, chronic obstructive lung diseases, Diabetes mellitus, chronic infections and hypertension. Patients with active bleeding or received blood transfusion four months prior to admission were also excluded.

\section{Methods}

Full clinical history and clinical examination were done for all patients. Hematological parameters were obtained for complete blood picture "CBC" using automatic cell counter "ADVIA ${ }^{\circledR} 2120 \mathrm{i}$ hematology System". The evaluated parameters included; white blood cell count $(\mathrm{WBC})$, hemoglobin $(\mathrm{Hb})$, platelet count (PLT), RDW and RDW/PLT ratio. The INR levels were also estimated. Biochemical parameters were done and included complete liver profile and serum creatinine indices. Assessment for the severity of liver disease was done by Child-Pugh and MELD scores. The diagnosis of HCC was based on abdominal 
ultrasound and typical criteria on multislice triphasic CT (MSCT) abdomen. Written informed consent was obtained from all patients before the participation of any investigation.

\section{Ethical consideration}

Written informed consent was obtained from all patients before the beginning of the study. The study was conducted following the provisions of the Declaration of Helsinki and was approved by the Ethical Committee of Faculty of Medicine, Assiut University.

\section{Statistical analysis}

Data entry and analysis were done using computerized SPSS version 21 (Statistical Package for Social Science). Data were presented as a number, mean and standard deviation. A chi-square test was used to compare qualitative variables such as sex and Child class. Mann-Whitney test was used to compare quantitative variables between groups. Correlation between RDW and RDW/PLT ratio with Child and MELD scores was done using the Pearson coefficient. P-value was considered statistically significant when $\mathrm{P}<$ 0.05 .

\section{RESULTS}

The demographic data of the 3 groups of patients (120 patients) are shown in Table 1 and the majority of them were males $(p=0.009)$. The laboratory data of the biochemical analysis of the liver profile tests, creatinine, INR, child class and MELD score were not significantly different except for child class $(p<0.000)$ and albumin $(p<0.000)$ level, which was elevated in group 3 who received DAAs. In addition, patients in group 3 showed not only elevated ALT and AST serum levels but also RBCs count $(p=0.004)$ compared to group 2 (Table 2).

RDW was relatively elevated in group 3 with $\mathrm{HCC}$ who received DAAs compared to group 1 and group 2 who did not receive DAAs (13.8 \pm 2.5 vs $13.6 \pm 2.3$ and $12.7 \pm 1.8$ ), respectively $(p=0.020)$ but this measure is still within the normal value. On the other side, RPR was decreased in group $1(0.12 \pm 0.04)$ but did not show a significant difference versus group 2 and group 3 ( $0.14 \pm 0.07$ vs $0.13 \pm 0.09)$.
The relation between RDW and the severity of cirrhosis in terms of Child-Pugh scores showed that RDW was increased in patients with HCC with viremia relative to HCC without viremia. This increase was shown in all Child classes with statistical significance in Child class $A$ and $B(p=$ 0.012 and 0.009 , respectively). In contradictory, RPR did not show significant changes in Child class $A$ and $B$ in both groups of $\mathrm{HCC}$ with a more elevated level in Child $C$ in HCC without viremia (Table 3). Meanwhile, elevated RPR level in Child C was observed in HCC group with SVR to DAAs (Table 3). Correlation between both RDW and RPR with other variables in groups 2 and 3 as shown in Tables 4 and 5 revealed that they were negatively correlated with hemoglobin level in group $3(p=0.046)$. In group 2 , RDW was positively correlated with bilirubin level, AST and MELD score but negatively correlated with albumin level. However, in group 3, there was a negative correlation with albumin.

\section{DISCUSSION}

The RDW value elevated when there is an increased RBC destruction or more commonly, ineffective production. These conditions are often present in patients with liver diseases, and correlated to the severity of the disease, and are associated with a worse prognosis (Lippi., et al. 2017). In a recent study, it was found that there is a significant increase in the RDW values of patients with anti-HCV positive. However, there was no comparison with patients treated with DAAs (Karabulut., et al.2019).

Persistence of HCV induces different innate and adaptive immune responses including a varied range of inflammatory cells and cytokines resulting in sustained inflammation and consequent liver injury and HCC (Baskic., et al. 2017). These inflammatory cytokines can cause impairment in RBC maturation, thus an increase in the heterogeneity of RBCs and a decrease in their half-life time (Chen., et al. 2013). As well established now, continuous injury to the liver parenchyma by chronic HCV is accompanied by the release of pro-inflammatory cytokines as interleukin-6 (IL-6) and tumor necrosis factoralpha (TNF- $\alpha$ ). IL- 6 constrains erythropoietin (EPO) production and downregulates its receptor, eventually impairing erythropoiesis and producing anisocytosis (Perlstein., et al. 2009). 
Table 1. The demographic data, biochemical parameters, child class and MELD score

\begin{tabular}{|c|c|c|c|c|}
\hline Item & Group 1, $(n=40)$ & Group 2, $(n=40)$ & Group 3, $(n=40)$ & p-value \\
\hline \multicolumn{5}{|l|}{ Age "yrs." } \\
\hline $\begin{array}{l}\text { Mean } \pm \text { SD } \\
\text { (Range) }\end{array}$ & $\begin{array}{l}60.35 \pm 12.023 \\
(22.0-85.0)\end{array}$ & $\begin{array}{l}59.58 \pm 7.615 \\
(36.0-74.0)\end{array}$ & $\begin{array}{l}61.05 \pm 7.130 \\
(40.0-76.0)\end{array}$ & $P=0.776$ \\
\hline \multicolumn{5}{|l|}{$\operatorname{Sex}(n, \%):$} \\
\hline - Male & 19 (47.5\%) & $23(57.5 \%)$ & $32(80 \%)$ & $P=0.009 *$ \\
\hline - Female & $21(52.5 \%)$ & $17(42.5 \%)$ & $8(20 \%)$ & \\
\hline Liver profile tests: & & & & $\mathrm{P}=0.924$ \\
\hline Bilirubin ( $\mu \mathrm{mol} / \mathrm{l})$ & $73.15 \pm 16.7$ & $70.06 \pm 17.4$ & $63.77 \pm 16.73$ & $\mathrm{P}<0.000^{*}$ \\
\hline $\operatorname{ALB}(g / l)$ & $23.68 \pm 0.92$ & $27.12 \pm 1.06$ & $32.12 \pm 1.33$ & $P=0.414$ \\
\hline ALT (IU/L) & $75.29 \pm 20.75$ & $45.59 \pm 4.22$ & $96.95 \pm 42.45$ & $P=0.724$ \\
\hline AST (IU/L) & $113.53 \pm 32.52$ & $85.88 \pm 6.68$ & $113.21 \pm 34.68$ & $P=0.90$ \\
\hline \multirow[t]{2}{*}{ S. Creat. $(\mu \mathrm{mol} / \mathrm{l})$} & $99.21 \pm 10.39$ & $102.60 \pm 15.44$ & $107.69 \pm 13.21$ & \\
\hline & & & & $P=0.293$ \\
\hline MELD score & $16.2 \pm 1.02$ & $15.45 \pm 0.755$ & $13.98 \pm 1.21$ & \\
\hline \multicolumn{5}{|l|}{ Child class (n, \%): } \\
\hline Child A & $3(7.5 \%)$ & 7 (17.5\%) & 19 (47.5\%) & $\mathrm{P}<0.000^{*}$ \\
\hline Child B & $17(42.5 \%)$ & $20(50 \%)$ & $10(25 \%)$ & \\
\hline Child C & $20(50 \%)$ & $13(32.5 \%)$ & $11(27.5 \%)$ & \\
\hline
\end{tabular}

Group 1: Liver cirrhosis without HCC or DAAs; Group 2: Liver cirrhosis and HCC with viremia and Group 3: Liver cirrhosis and HCC without viremia,

Group 1: Liver cirrhosis without HCC or DAAs; Group 2: Liver cirrhosis and HCC with viremia and Group

3: Liver cirrhosis and HCC without viremia;

ALB: Albumin, ALT: Alanine aminotransferase, AST: Aspartate amiotransferase.

Data are presented as numbers(percent) and mean \pm standard deviation.

* Significant $p$ value $<0.05$.

Table 2. The CBC, RDW \% and other hematological parameters of the included patient groups ( $n=40 /$ each) in the study.

\begin{tabular}{|c|c|c|c|c|c|c|}
\hline $\begin{array}{c}\text { Item } \\
\left(10^{x} / \mathrm{mm}^{3}\right)\end{array}$ & $\begin{array}{l}\text { Group } 1 \\
(X \pm S D)\end{array}$ & $\begin{array}{l}\text { Group } 2 \\
(X \pm S D)\end{array}$ & $\begin{array}{l}\text { Group } 3 \\
(X \pm S D) \\
\end{array}$ & P1-value & P2-value & P3-value \\
\hline WBCs $\left(10^{3}\right)$ & $6.8 \pm 2.5$ & $6.3 \pm 3.3$ & $8.4 \pm 15.2$ & $\mathrm{P}=0.172$ & $P=0.166$ & $P=0.866$ \\
\hline $\operatorname{RBCs}\left(10^{6}\right)$ & $3.8 \pm 0.7$ & $3.7 \pm 0.7$ & $4.5 \pm 1.9$ & $P=0.447$ & $\mathrm{P}=0.037^{*}$ & $\mathrm{P}=0.004^{*}$ \\
\hline $\mathrm{Hb}(\mathrm{g} / \mathrm{l})$ & $11.0 \pm 1.1$ & $11.1 \pm 1.8$ & $11.9 \pm 2.3$ & $P=0.7$ & $P=0.124$ & $P=0.182$ \\
\hline Platelets $\left(10^{3}\right)$ & $129 \pm 51.4$ & $138 \pm 95.2$ & $135.4 \pm 79.1$ & $P=0.497$ & $P=0.836$ & $P=0.690$ \\
\hline RDW (\%) & $13.6 \pm 2.3$ & $12.7 \pm 1.8$ & $13.8 \pm 2.5$ & $P=0.07$ & $P=0.725$ & $P=0.020^{*}$ \\
\hline RPR & $0.12 \pm 0.04$ & $0.13 \pm 0.09$ & $0.14 \pm 0.07$ & $P=0.736$ & $P=0.855$ & $P=0.900$ \\
\hline INR & $1.58 \pm 0.07$ & $1.47 \pm 0.04$ & $1.46 \pm 0.09$ & $P=0.343$ & $P=0.005^{*}$ & $\mathrm{P}=0.020^{*}$ \\
\hline
\end{tabular}

WBCs: White blood cells, RBCs: Red blood cells, Hb: Hemoglobin concentration, RDW: Red cell distribution width, RPR: the ratio of Red cell distribution width/platelets and (International Normalized Ratio) INR indices. P1-value: Probability of difference between group 1 and group 2,

P2-value: Probability of difference between group 1 and group 3 ,

P3-value: Probability of difference between group 2 and group 3.

* Significant at $\mathrm{p}<0.05$.

Table 3. The relationship between red blood distribution width (RDW), RDW/platelets ratio (RPR) with respect to the severity of the liver cirrhosis in children with hepatocellular carcinoma (HCC).

\begin{tabular}{|c|c|c|c|c|c|c|}
\hline \multirow{2}{*}{ Child class } & \multicolumn{3}{|c|}{ RDW } & \multicolumn{2}{c|}{ RPR } \\
& HCC with viremia & HCC without viremia & P-value & HCC with viremia & HCC without viremia & P-value \\
\hline Child A & $11.7 \pm 0.31$ & $12.89 \pm 0.25$ & $0.012^{*}$ & $0.123 \pm 0.02$ & $0.116 \pm 0.02$ & 0.34 \\
\hline Child B & $12.4 \pm 0.38$ & $15.21 \pm 0.93$ & $0.009^{*}$ & $0.140 \pm 0.03$ & $0.157 \pm 0.04$ & 0.660 \\
\hline Child C & $13.7 \pm 0.53$ & $14 \pm 1.01$ & 0.794 & $0.129 \pm 0.02$ & $0.163 \pm 0.03$ & 0.622 \\
\hline
\end{tabular}

Data are presented as mean \pm standard deviation, Mann-Whitney test was used to compare quantitative variables between groups, * Significant at $p<0.05$ 
Table 4. Correlation between RDW and RPR with reference to other variables in HCC patients with viremia.

\begin{tabular}{|c|c|c|c|}
\hline Variables & $\begin{array}{c}\text { Correlation factor } \\
(\mathbf{r}) / \text { P-value }\end{array}$ & RDW & RPR \\
\hline \multirow{2}{*}{ RBCs } & $\mathrm{r}$ & 0.114 & -0.070 \\
\hline \multirow{2}{*}{ HB } & $\mathrm{p}$ & 0.484 & 0.666 \\
\hline \multirow{2}{*}{ Bilirubin } & $\mathrm{r}$ & -0.199 & -0.138 \\
\hline \multirow{2}{*}{ Albumin } & $\mathrm{p}$ & 0.219 & 0.395 \\
\hline \multirow{2}{*}{ ALT } & $\mathrm{r}$ & 0.248 & -0.036 \\
\hline \multirow{2}{*}{ AST } & $\mathrm{p}$ & 0.122 & 0.824 \\
\hline \multirow{2}{*}{ INR } & $\mathrm{p}$ & -0.268 & -0.071 \\
\hline \multirow{2}{*}{ MELD score } & $\mathrm{r}$ & 0.094 & 0.665 \\
& $\mathrm{p}$ & 0.228 & -0.045 \\
\hline & $\mathrm{p}$ & 0.157 & 0.782 \\
\hline & $\mathrm{r}$ & 0.476 & -0.048 \\
\hline & $\mathrm{p}$ & 0.021 & 0.770 \\
\hline & $\mathrm{p}$ & 0.875 & -0.019 \\
\hline
\end{tabular}

Correlation was done using the Pearson coefficient, Significant at $p<0.05$.

Table 5 Correlation between RDW and RPR with reference to other variables in patients with viremia and HCC received DAAs with SVR12.

\begin{tabular}{|c|c|c|c|}
\hline Variables & $\begin{array}{l}\text { Correlation factor } \\
\text { (r) / P-value }\end{array}$ & RDW & RPR \\
\hline \multirow{2}{*}{ RBCs } & $r$ & 0.134 & 0.142 \\
\hline & $p$ & 0.409 & 0.384 \\
\hline \multirow{2}{*}{$\mathrm{HB}$} & $r$ & -0.317 & -0.023 \\
\hline & $p$ & $0.046^{*}$ & 0.169 \\
\hline \multirow{2}{*}{ Bilirubin } & $r$ & -0.036 & 0.111 \\
\hline & $p$ & 0.827 & 0.497 \\
\hline \multirow{2}{*}{ Albumin } & $r$ & -0.217 & -0.221 \\
\hline & $p$ & 0.185 & 0.176 \\
\hline \multirow{2}{*}{ ALT } & $r$ & -0.136 & -0.020 \\
\hline & $p$ & 0.404 & 0.903 \\
\hline \multirow{2}{*}{ AST } & $r$ & -0.107 & 0.028 \\
\hline & $p$ & 0.513 & 0.865 \\
\hline \multirow{2}{*}{ INR } & $r$ & 0.197 & 0.311 \\
\hline & $p$ & 0.224 & 0.051 \\
\hline \multirow{2}{*}{ MELD score } & $r$ & -0.028 & 0.155 \\
\hline & $p$ & 0.862 & 0.339 \\
\hline
\end{tabular}

Correlation was done using the Pearson coefficient, * Significant $p$-value $<0.05$

In the current study, RDW was relatively elevated in patients with HCC who had DAAs therapy than patients with HCC without DAAs therapy $(P=0.020)$. Additionally, these values are still within the normal values of RDW. This change cannot be attributed to anemia alone as the means of $\mathrm{Hb}$ level were almost similar in both groups. The elevated levels of ALT and AST in patients who received DAAs than those who did not receive DAAs could reflect an ongoing inflammatory reaction in both liver and bone marrow, which are involved in erythropoiesis process that maintained the RDW.
A study (Hengst., et al. 2016) showed that chronic HCV infection disturbs the setting of inflammatory mediators even after SVR with DAAs, suggesting that the inflammatory alterations induced by HCV are not fully reversible after clearance of the virus. Moreover, this relatively maintained level of RDW in HCC in the presence and absence of HCV viremia could be related to the mere presence of HCC.

The exact mechanisms between increased RDW and cancer remain unclear. It seems that the increased RDW is related to the chronic 
inflammatory response, which plays an important role in the pathogenesis of cancer (Coussens and Werb 2002). The elevated RDW in HCC patients may be explained by other mechanisms such as malnutrition, which is generally a common occurrence in patients with cancer (Nicolini., et al. 2013). For example, low serum folate and vitamin B12 were observed in HCC patients (Kuo., et al. 2008) and it is wellrecognized that their deficiencies can affect RBC heterogeneity (Toprak., et al. 2014).

AS RDW and RPR could predict the presence of cirrhosis, they also could be considered along with other biomarkers to estimate the severity of HCV infection (He., et al. 2016). In this study, RDW was higher in patients who had HCC and received DAAs therapy in all Child classes with statistical significance in Child class $A$ and $B$ with a higher RDW in child class B (15.2 \pm 0.93$)$. Similarly, (Luo, Rong et al. 2019) reported that RDW was higher inpatient Child class $B$ and $C$ with HCC $(15.3 \pm 2.98)$ than Child class A $(14.4 \pm$ 2.7).

In this study the RDW is positively correlated with bilirubin level, AST and MELD score but negatively correlated with albumin level in patients with HCC without DAAs. This is in accordance with (Wei., et al. 2016) who reported, in a retrospective analysis, that RDW was negatively correlated with albumin and positively correlated with serum bilirubin and prothrombin time with RDW significantly elevated with the advance of Child-Pugh stage. In this respect, they concluded that RDW is elevated in HCC patients and it is a useful index to assess the liver functions.

On the other hand, RPR obtained from this study was not significantly different among patient groups with HCC and was not correlated with Child class. The value of RPR could be influenced by changes in platelets count which could be increased in $\mathrm{HCC}$ as platelet counts can be elevated in HCC patients with cirrhosis, compared to HCC-free cirrhotic controls (Zanetto., et al. 2017).

To the best of our knowledge, this is the first study to assess possible changes in RDW in patients with HCC in the presence and absence of HCV viremia. Nevertheless, limitations of this study include the relatively small sample size and lack of measurement of serum folate, vitamin B12 or iron which are involved in erythropoiesis and could reflect malnutrition that increases RDW.

\section{CONCLUSION}

Clearance of HCV following DAAs did not have a major impact on the level of RDW in patients who developed HCC after DAAs therapy. The clinical value of RDW in these patients was not different from patients with HCC with viremia. Moreover, RDW changes were related to the severity of liver disease. Further prospective multicenter studies on a larger sample size should be carried out to confirm the clinical value of RDW in patients receiving DAAs.

\section{ACKNOWLEDGMENTS}

Brief acknowledgments of persons who have made genuine contributions to the manuscript and who endorse the data and conclusions should be included. Authors are responsible for obtaining written permission to use any copyrighted text and/or illustrations.

\section{CONFLICT OF INTEREST}

All authors declared no conflicts of interest.

\section{FUNDING}

No fund was received for this work.

\section{REFERENCES}

Balta S., Aydogan M., Demirkol S., Cakar M., Akgul E.O. and Sarlak H. (2014). Red cell distribution width: a novel and simple predictor of mortality in chronic obstructive pulmonary disease. COPD 11(4): 475-476.

Baskic D, Vukovic VR, Popovic S, Djurdjevic P, Zaric M, Nikolic I, Zelen I, Mitrovic M, Avramovic D and Mijailovic Z (2017). Cytokine profile in chronic hepatitis C: An observation. Cytokine 96: 185188.

Chen B, Ye B, Zhang J, Ying L and Chen Y (2013). RDW to platelet ratio: a novel noninvasive index for predicting hepatic fibrosis and cirrhosis in chronic hepatitis B. PloS one 8(7): 768-780.

Coussens L M and Werb Z (2002). Inflammation and cancer. Nature 420(6917): 860-867.

European Association for Study of Liver (2014). EASL Clinical Practice Guidelines: management of hepatitis C virus infection. J Hepatol 60(2): 392420.

Falade-Nwulia O, Suarez-Cuervo C, Nelson DR, Fried M W, Segal JB and Sulkowski MS (2017). Oral 
direct-acting agent therapy for hepatitis $C$ virus infection: a systematic review. Ann Inten Med.166(9): 637-648.

Goyal H, and Hu Z D (2017). Prognostic value of red blood cell distribution width in hepatocellular carcinoma. Ann Transl Med. 5(13).

He Q, He Q, Qin X, Li S, Li T, Xie L, Deng Y, He Y, Chen $Y$ and Wei $Z$ (2016). The relationship between inflammatory marker levels and hepatitis $C$ virus severity. Gastroenterol Res Pract.

Hengst J, Falk CS, Schlaphoff V, Deterding K, Manns MP, Cornberg M and Wedemeyer H (2016). Direct-acting antiviral-induced hepatitis $C$ virus clearance does not completely restore the altered cytokine and chemokine milieu in patients with chronic hepatitis C. J Infect Dis. 214(12): 1965-1974.

Karabulut N, Ayyıldız H, Bayrak $\mathrm{H}$ and Kalaycı M (2019). Evaluation of red cell distribution width in anti-hcv positive patients. EJPMR 6(2): 161-164.

Karagöz E, Tanoğlu A, Ülçay A, Erdem H, Turhan V, Kara $M$ and Yazgan $Y$ (2016). Mean platelet volume and red cell distribution width to platelet ratio for predicting the severity of hepatic fibrosis in patients with chronic hepatitis C. Eur J Gastroentero Hepatol.28(7): 744-748.

Ku, N.S., H.-w. Kim, H.J.Oh, Y.C. Kim, M.H. Kim, J.E. Song, D.H. Oh, J.Y. Ahn, S.B. Kim and S.J. Jeong (2012). Red blood cell distribution width is an independent predictor of mortality in patients with gram-negative bacteremia. Shock 38(2): 123-127.

Kuo CS, Lin CY, Wu MY, Lu CL and Huang RF (2008). Relationship between folate status and tumour progression in patients with hepatocellular carcinoma.Br J Nutr. 100(3): 596-602.

Lippi G, Mattiuzzi C and Cervellin G (2017). Learning more and spending less with neglected laboratory parameters: the paradigmatic case of red blood cell distribution width. Acta Biomed 87(3): 323-328.

Lippi G and Plebani M (2014). Red blood cell distribution width (RDW) and human pathology. One size fits all. Clin Chem Lab Med. 52(9): 12471249.

Lou Y, Wang M and Mao W (2012). Clinical usefulness of measuring red blood cell distribution width in patients with hepatitis $B$. PloS one 7(5): e37644.

Luo C L, Rong Y, Chen H, Zhang W W, Wu L, Wei D, Wei X Q, Mei L J and Wang F B (2019). A Logistic Regression Model for Noninvasive Prediction of AFP-Negative Hepatocellular Carcinoma. Technol Cancer Res Treat. ,18:1-8.

Nicolini A, Ferrari P, Masoni MC, Fini M, Pagani S, Giampietro $O$ and Carpi A (2013). Malnutrition, anorexia and cachexia in cancer patients: a mini- review on pathogenesis and treatment.Biomed Pharmacother. 67(8): 807-817.

Perlstein TS, Weuve J, Pfeffer MA and Beckman JA (2009). Red blood cell distribution width and mortality risk in a community-based prospective cohort. Arch Intern Med.169(6): 588-594.

Purtle S W, Moromizato T, McKane C K, Gibbons F K and Christopher K B (2014). The association of red cell distribution width at hospital discharge and out-of-hospital mortality following critical illness.Crit Care Med. 42(4): 918-929.

Rawla P, Sunkara T, Muralidharan $P$ and Raj JP (2018). Update in global trends and aetiology of hepatocellular carcinoma. Contemp Oncol (Pozn) 22(3): 141-150.

Salvagno G L, Sanchis-Gomar F, Picanza A and Lippi G (2015). Red blood cell distribution width: A simple parameter with multiple clinical applications.Crit Rev Clin Lab Sci. 52(2): 86-105.

Taefi A, Huang CC, Kolli K, Ebrahimi S and Patel M (2015). Red cell distribution width to platelet ratio, a useful indicator of liver fibrosis in chronic hepatitis patients. Hepatol Int.9(3): 454-460.

Thandassery RB, Al Kaabi S, Soofi ME, Mohiuddin SA, John AK, Al Mohannadi M, Al Ejji K, Yakoob R, Derbala MF and Wani $H$ (2016). Mean platelet volume, red cell distribution width to platelet count ratio, globulin platelet index, and 16 other indirect noninvasive fibrosis scores: how much do routine blood tests tell about liver fibrosis in chronic hepatitis C. I Clin Gastroenterol 50(6): 518-523.

Toprak B, Yalcın H and Colak A (2014). Vitamin B12 and folate deficiency: should we use a different cutoff value for hematologic disorders. Int J Lab Hematol. 36(4): 409-414.

Uyarel H, Isik T, Ayhan E and Ergelen M (2012). Red cell distrubition width (RDW): a novel risk factor for cardiovascular disease. Int J Cardiol. 154(3): 351-352.

Wang $\mathrm{H}$, Xu H, Wang X, Wu R, Gao X, Jin Q and Niu J (2016). Red blood cell distribution width to platelet ratio is related to histologic severity of primary biliary cirrhosis. Medicine 95.11.

Wei TT, Tang QQ, Qin BD, Ma N, Wang LL, Zhou L and Zhong RQ (2016). Elevated red blood cell distribution width is associated with liver function tests in patients with primary hepatocellular carcinoma. Clin Hemorheol Microcirc 64(2): 149-155.

Zanetto A, Senzolo M, Vitale A, Cillo U, Radu C, Sartorello F, Spiezia L, Campello E, RodriguezCastro K and Ferrarese A (2017). Thromboelastometry hypercoagulable profiles and portal vein thrombosis in cirrhotic patients with hepatocellular carcinoma. Dig Liver Dis. 49(4): 440-445. 



\section{Egyptian Association for Cancer Research (EACR)}

http://eacr.tanta.edu.eg/

EACR is an NGO society that was declared by the Ministry of Social Solidarity (Egypt) No. 1938 in 19/11/2014 based on the initiative of Prof. Mohamed Labib Salem, the current Chairman of EACR. EACR aims primarily to assist researchers, in particular young researchers in the field of cancer research through workshops, seminars and conferences. Its first international annual conference entitled "Anti-Cancer Drug Discovery" was successfully organized in April 2019 (http://acdd.tanta.edu.eg). Additionally, EACR aims to raise the awareness of the society about the importance of scientific research in the field of cancer research in prediction, early diagnosis and treatment of cancer. EACR is also keen to outreach the scientific community with periodicals and news on cancer research including peer-reviewed scientific journals for the publication of cutting-edge research. The official scientific journal of EACR is "International Journal of Cancer and biomedical Research (IJCBR: https://jcbr.journals.ekb.eg) was successfully issued in 2017 and has been sponsored by the Egyptian Knowledge Bank (EKB: www.ekb.eg).

\section{EACR Chairman,}

Prof. Mohamed Labib Salem, PhD

Professor of Immunology

Faculty of Science, Tanta Universiy, Egypt 


\section{GUIDE FOR AUTHORS}

Publisher :The International Journal of Cancer and Biomedical Research (IJCBR) is an International and interdisciplinary journal of preclinical and clinical studies in the area of cancer and biomedical research. It is a peer-reviewed journal in English, published quarterly (in March, June, September, and December) by the Egyptian Association for Cancer Research (EACR) in both print and online formats (4 issues making a volume). Special issues or supplements may also be produced from time to time upon agreement with the Editorial Board.

Scope :The main aim of IJCBR is to attract the best research in animal and human biology in health and diseases from across the spectrum of the biomedical sciences at the molecular, cellular, organ, and whole animal levels especially those that are related to cancer research, including causes, prediction, diagnosis, prognosis, and therapy.

Publication Fees :The journal does charge for submission, processing, or publication of manuscripts (2000 LE for Egyptians or $250 \$$ for non-Egyptians; EACR members receive 15\% discount on publication). Of them Peer-review fees (300 LE) should be paid on submission (non-refundable). For the fast-track production of the accepted manuscript, another 500 LE is paid.

General specifications for different types of article

- Submitted manuscripts should not have been published previously, except in a limited form (e.g. short communication to a symposium or as part of MSc or PhD theses) and should not be under consideration for publication by other journals.

- All co-authors should agree with the content of the manuscript. Authors must have obtained permission to use any copyrighted material in the manuscript before submission.

IJCBR publishes different types of articles

- Original Article (6000 words with $\mathbf{4}$ tables and $\mathbf{4}$ figures, maximum $\mathbf{8}$ display items): Articles with novel findings are the target of IJCBR. Articles presenting a detailed description of a new technique, comparison of existing methods, meta-analyses with comprehensive and in-depth discussion are considered. Papers in a numbered series are not accepted unless all are submitted at the same time.

- Short communications or case study (3000 words with $\mathbf{4}$ display items): Short communications present exceptionally exciting, novel or timely contents are considered. They will be peer-reviewed in the same way as research papers. The references are restricted to 15 .

- Reviews or systematic review (9000 words with $\mathbf{1 0}$ display items): They are invited by the Editorial Board or unsolicited. Review articles have to be contemporary and comprehensive and add information to the knowledge. Sharp critical analyses of novel data or concepts are encouraged. When relevant, a statistical analysis of data and a meta-analysis approach are recommended.

- Opinion papers, letter to the editor or comment to the editor (1500 words with $\mathbf{2}$ display items): They are submitted by invitation of the Editorial Board. They are short papers, which aim to inform scientists, industry, and the public and policymakers about cutting-edge issues in research or the impact of research. They reflect the opinion of their authors who bear full responsibility of the published paper. The references are restricted to 10 .

- Conference/Symposium papers: The journal will consider for publication the results of original work and critical reviews that are presented at conferences/symposia. Symposium organizers who wish to publish bundles of papers from a symposium/conference in IJCBR should first contact the Editor-in-Chief of the IJCBR (EACR@unv.tanta.edu.eg) for agreement. Supplementary material can be proposed and will be made available online. The responsibility for the preparation of a paper in a form suitable for publication lies with the author.

- Thesis: IJCBR can publish the summary and abstract of Master and PhD theses in a special issue.

English: Good quality of written English is required. Spelling may be in British or American English but must be consistent throughout the paper. Care should be exercised in the use of biological terminology that is ill-defined or of local familiarity only. We recommend that authors have their manuscripts checked by an English language native speaker before submission.

Manuscript layout: Manuscripts should be prepared using a standard word processing program and presented in a clear readable format with easily identified sections and headings. The manuscript layout is based on the following directions.

- The main text contains Title, Abstract, Keywords, Introduction, Material and Methods, Results, Discussion, References, Tables, figures.

- The title needs to be concise and informative. Use bold, with an initial capital for the first word only and for words that ordinarily take capitals.

- Short (running) title (max 80 characters including spacing).

- The article text should be typed with double line spacing with wide margins $(2.5 \mathrm{~cm})$.

- The lines must be continuously numbered; the pages must also be numbered.

- Font Calibri 12 should be used for the text, and 12 for the tables, figure legends and references.

- The sections should typically be assembled in the following order:

- Title page contains title, authors' names, full affiliations, acknowledgements and the corresponding author's contacts and Short title.

Abstract (max 250 words, single paragraph): The abstract should be complete and understandable without citation, references, table, or figure. Use structured abstract: Background, Aim, Materials \& Methods, Results and Conclusion. The context and the rationale of the study are presented succinctly to support the objectives. The experimental methods and main results are summarized but should not be overburdened by numerical values or probability values. The abstract ends with a short and clear conclusion. 
Keywords: Up to five short and specific keywords should complement the title with respect to indicating the subject of the paper in alphabetic order.

Introduction: The introduction briefly outlines the context of the work, presents the current issues that the authors are addressing and the rationale to support the objectives, and clearly defines the objectives.

Material and methods: Material and methods should be described in sufficient details so that others can repeat the experiment. Reference to previously published work may be used to give methodological details, provided that said publications are readily accessible and in English. The code of ethics should be followed for all experiments use animals or human samples.

Statistical analysis of results: The statistical design and the models of statistical analysis must be described, as well as each of the statistical methods used. Sufficient statistical details must be given to allow replication of the statistical analysis. The experimental unit should be defined (e.g., individual or group of animals).

Results: Data are presented as tables and figures. Brief description of the results for each table and figure should be presented. Unpublished data can be mentioned when necessary.

Discussion: Should be separate from the Results section and should focus only on intra- and inter-data discussion (the data in the results section) as well as with the relative data in the literature. Don't repeat information already presented in the Introduction section. Start the first paragraph in the Discussion with a paragraph stating the rationale behind the study, the objectives, and the main findings. End Discussion with a short conclusion.

Acknowledgements: In this section, the authors may acknowledge (briefly) their support staff.

Conflict of interest: All papers with a potential conflict of interest must include a description/explanation in a separate heading.

Funding details: The authors should state the source of findings of the study (with research funder and/or grant number). If no fund, the authors should state that the study is self-funded.

\section{References}

Citation of references: In the text, references should be cited by the author(s) surname(s) and the year of publication (e.g. Salem, 2020). References with two authors should be cited with both surnames (e.g. Salem and Meshrif, 2021). References with three or more authors should be cited with the first author followed by et al. (in italics; e.g. Salem et al., 2021). Names of organizations used as authors (e.g. Food and Drug Administration) should be written out in full in the list of references and on the first mention in the text. Subsequent mentions may be abbreviated (e.g. FDA).

- List of references. Literature cited should be listed in alphabetical order by authors' names. It is the author's responsibility to ensure that all references are correct. All authors should be written and so the full journal name.

- $\quad$ References from journal articles are formatted in APA as this example: Al-Amoudi WM (2018). Toxic effects of Lambdacyhalothrin on the rat thyroid. Involvement of oxidative stress and ameliorative effect of ginger extract. Toxicology Reports, 5: 728-736.

- $\quad$ References from books or official reports are formatted as this example. Kebreab E, Dijkstra ANM, Bannink A, Gerrits WJJ, \& France J (2006). Nutrient digestion and utilization in farm animals. CABI Publishing. Wallingford, UK.

- References from chapters or parts of books are formatted as this example. Nozière $P, \&$ Hoch $T$ (2006). Modelling fluxes of volatile fatty acids from rumen to portal blood. In: Nutrient digestion and utilization in farm animals (Kebreab E, Dijkstra ANM, Bannink A, Gerrits WJJ \& France J, eds.), pp. 40-47. CABI Publishing. Wallingford, UK.

Tables: The data should be presented in tables or in graphs, not both.

- Each table should be placed on a separate page at the end of the main text.

- Tables are numbered consecutively using Arabic numbering. They are referred to as Table 1 , Table 2, etc., with capital ' $T$ ', no italics

- $\quad$ Each table has its explanatory caption. The caption is sufficient to permit the table to be understood without reference to the text.

- Abbreviations used in tables/figures have to be defined either as footnotes or in the caption.

\section{Figures}

- $\quad$ Package the figures in a single PowerPoint file. Each figure in a separate slide.

- Figure size should be readable in a width of approximately 8-175 $\mathrm{mm}$ (i.e. the maximum size of printing over two columns).

- Ensure that the font size is large enough to be readable at the final print size, use Calibri font to ensure that they are consistent throughout the figures.

- $\quad$ The figures should preferably be provided as TIFF or EPS files.

- The resolutions of figures must be at least $300 \mathrm{dpi}$.

- Preparation of images for a manuscript: For guidance, we refer to the Journal of Cell Biology's instructions to authors (http://jcb.rupress.org/site/misc/ifora.xhtml\#image_aquisition).

- If a cropped image is included in the main text of a paper (e.g. a few lanes of a gel), display the full original image, including the appropriate controls, the molecular size ladder and/or the scale as relevant, as a single figure in a Supplementary Material file to facilitate peer-review and for subsequent online publication.

- Supplementary material is submitted along with the main manuscript in a separate file and identified at uploading as "Supplementary File - for Online Publication Only" The title of the article is included at the top of the supplementary material.

Corresponding author's guidelines: Upon acceptance the corresponding author is required to send his/her recent formal photo to be attached to the front page of the article. 


\title{
International Journal of Cancer \& Biomedical Research
}

(IJCBR) Online ISSN 2682-2628

\author{
Editor-in-Chief \\ Mohamed Labib Salem, PhD \\ Tanta University, Egypt
}

\begin{tabular}{l} 
EACR Board \\
\hline Nehal Elmashad, MD \\
Tanta University, Egypt \\
Nabil Mohy Eldin, PhD \\
Kafrelsheikh University, Egypt \\
Doaa Al-Ghareeb, PhD \\
Alexandria University, Egypt \\
Abdel-Aziz Zidan, PhD \\
Damanhour University, Egypt
\end{tabular}

\begin{tabular}{l} 
Managing Editor \\
\hline Wesam Meshrif, PhD \\
Tanta University, Egypt \\
Sohaila Galal, PhD \\
Tanta University, Egypt \\
Production and Contact \\
\hline Hamdi Kandil \\
Tanta University, Egypt \\
Email: ljcbr100@gmail.com
\end{tabular}

\section{Advisory Board}

Alberto Montero, MD

Taussig Cancer Center, Cleveland,

USA

Yi Zhang, MD

Zhengzhou University, China

Mark Robunstein, Ph D

Medical University of South

Carolina, USA

Mohsen Farid, Ph D

Derby University, USA

Natarajan Muthusamy, Ph D

Ohio State University, USA

Hideki Kasuya, MD

Nagoya University, Japan

Sherif El-Khamisy, Ph D

Sheffield University, UK

Mohamed Ghanem, Ph D

Kafr Elshikh University, Egypt

Sayed Bakry, Ph D

Alazhar University, Egypt

Sameh Ali, Ph D

Nationa Liver Institute, Egypt

Gamal Badr, Ph D

Assuit University, Egypt

Nadia Hamdy, Pharm D

Ain Shams University, Egypt

\section{Editorial Board}

\section{Clinical studies}

Hesham Tawfik, MD

Tanta University, Egypt

Mohamed Attia, MD

Tanta University, Egypt

Mohamed Elshanshory, MD

Tanta University, Egypt

Essam Elshiekh, MD

Tanta Cancer Center, Egypt

Rasha Eraky, MD

Tanta University, Egypt

Shaima Abou-Kjatwa, MD

Tanta University, Egypt

Marcela Diaz, MD

Cleveland Clinic Foundation, USA

Mohamed Abou-El-Enein, MD

Charité Universitätsmedizin Berlin,

Germany
Alaa Eldin Almostafa, MD

McGill University, Canada

Olfat Gadallah, MD

Tanta University, Egypt

Nagla Sarhan, MD

Tanta University, Egypt

Naglaa Fathy, Pharm D

Zagazik University, Egypt

Mohamed Salama, MD

Mansoura University, Egypt

Mona Marie, MD

Alexandria University, Egypt

Preclinical studies

Mostafa El-Sheekh

Tanta University, Egypt

El-Refai Kenawy, Ph D

Tanta University, Egypt

Mohamed Noureldin, Ph D

Banaha University, Egypt

Yousry Albolkiny, Ph D

Tanta University, Egypt

Elsayed Salim, Ph D

Tanta University, Egypt

Shengdian Wang, Ph D

Chinese Academy of Sciences,

China

Sabry El Naggar, Ph D

Tnata Univesity, Egypr

Faris Alenzi, Ph D

Prince Sattam bin Abdulaziz

University, KSA

Ibrahim El-Sayed, Ph D

Menoufia University, Egypt

Tarek Aboul-Fadl, Ph D

Assiut University, Egypt

Rabab Khairat, Ph D

National Research Center,

Giza, Egypt

Wael Lotfy, Ph D

Alexandria University, Egypt

Ashraf Tabll, Ph D

National Research Center, Egypt

Nahla Shoukry, Ph D

Suez University, Egypt
Medhat Eldenary, Ph D

Tanta University, Egypt

Azza Hasan, Ph D

Menufia University, Egypt

Nanees Gamal Eldin, Ph D

Tanta University, Egypt

Mohamed Mansour, UK

Sabbah Hammoury, Ph D

Alexandria Ayadi Almostaqba

Oncology Hospital, Egypt

Nehal Aboulfotoh, Ph D

Zewail City for Science and

Technology, Cairo, Egypt

Amir Elkhami, Ph D

Galaxo, San Francisco, USA

Ahmed Alzohairy, Ph D

Zagazi University, Egypt

Wgady Khalil, Ph D

National Research Center, Egypt

Amr Amin, Ph D

United Arab Emirates

University, UAE

AbdelRahman Zekri, Ph D

National Cancer Institute, Egypt

Hussein Khamis, Ph D

Alexandria University, Egypt

Magdy Mahfouz, Ph D

Kafr Elsheikh University, Egypt

Ehab Elbedewey, Ph D

Tanta University, Egypt

Abeer Badr, Ph D

Cairo University, Egypt

Mamdooh Ghoneum, Ph D

Charles Drew University of

Medicine \& Science, USA

Haiam Abou Elela, Ph D

National Institute of Oceanography and Fisherie, Egypt

Maha EL-Demellawi, Ph D City for Scientific Research \&

Technology Applications, Egypt

Desouky Abd-El-Haleem, Ph D

City for Scientific Research \&

Technology Applications, Egypt 